\title{
The Role of Magnetic Resonance Imaging in Assessing Instability After Anterior Cruciate Ligament Reconstructive Surgery in Males
}

\author{
HANAN M. EISA, M.D.; RASHA S. HUSSEIN, M.D. and HOSAM M. AHMED EID, M.Sc. \\ The Department of Radiodiagnosis, Faculty of Medicine, Ain Shams University
}

\begin{abstract}
Background: The most commonly reconstructed ligament in the knee is the anterior cruciate ligament. Clinical evaluation of ACL reconstructions can be difficult, and MR imaging plays an important role in assessing instability of the knee joint after ACL reconstruction.

Aim of Study: To determine the value of magnetic resonance imaging in assessing instability after anterior cruciate ligament reconstructive surgery in males.

Patients and Methods: This prospective study included 30 male patients with reconstructed and repaired anterior cruciate ligaments of the knee, all of them were males. Their ages ranged from 19 to 58 years old with mean age of 30 years old.

Results: MRI is ideally suited for the evaluation of instability in the post-operative ACL patient. Graft integrity and position can be determined, and clinically challenging diagnoses such as graft impingement or hardware failure are readily diagnosed with MRI. With the increasing prevalence of arthroscopic repair of the ACL, the importance of MRI in the evaluation of this patient population will increase.

Conclusion: We conclude that MRI of the knee is valuable in assessing instability of the knee joint of the post-operative ACL reconstruction patient. MRI provides a non-invasive modality for evaluation of ACL graft fiber integrity and postoperative complications. ACL graft complications such as abnormal tunnel positioning, roof impingement, partial and complete graft tears, arthrofibrosis and tunnel synovial cysts, are reliably assessed by MRI.
\end{abstract}

Key Words: Magnetic resonance imaging - Anterior cruciate ligament - Knee instability.

\section{Introduction}

THE most commonly reconstructed ligament in the knee is the ACL. Clinical evaluation of ACL reconstructions can be difficult, and MR imaging plays an important role in assessing instability after ACL reconstruction [1].

Correspondence to: Dr. Hanan M. Eisa, The Department of Radiodiagnosis, Faculty of Medicine, Ain Shams University
Imaging studies includes plain radiographs which are usually negative, arthrograms which have generally been replaced by Magnetic Resonance Imaging (MRI) which has a sensitivity of 90-98\% for ACL graft complications [2] .

MRI is critical in evaluation of the postoperative knee, particularly in the assessment of instability of the anterior cruciate ligament reconstructed knee. MRI allows direct evaluation of the anterior cruciate ligament graft, the bone tunnels, and of additional disorders of the knee. MRI can demonstrate graft failure, bone tunnel position, impingement, and arthrofibrosis, as well as other causes of unsatisfactory outcome [3] .

\section{Aim of the work:}

The aim of this work is to determine the value of magnetic resonance imaging in assessing instability after anterior cruciate ligament reconstructive surgery in males.

\section{Patients and Methods}

This prospective study included 30 patients with reconstructed and repaired anterior cruciate ligaments of the knee, all of them were males. Their ages ranged from 19 to 58 years old with mean age of 30 years old.

Informed consents from the patients were obtained and the Medical Research Ethics Committee of Ain-Shams University approved the current study. It was conducted at the Radiology Departments of Ain-Shams University Hospitals (MRI unit) from January 2017 to October 2018. All patients were referred from Orthopedic Department in Ain-Shams University Hospitals and outpatient clinic. 


\section{The inclusion criteria were:}

Male patients who underwent anterior cruciate ligament reconstruction.

\section{Exclusion criteria were:}

- Patients who have a heart pacemaker or metallic foreign body in their eye.

- Patients who have an aneurysm clip in their brain or any electrically or magnetically activate implants (cochlear implants).

- Patients with severe claustrophobia.

- Uncooperative patients with excessive motion.

- Bad general conditions.

- Sampling method all patients were referred from Orthopedic Department in Ain-Shams University Hospitals and Outpatient Clinic.

- Sampling size 30 male patients were included.

- Informed consents from the patients were obtained.

\section{All patients were subjected to:}

Full history taking and thorough clinical examination including:

- Name and age.

- Clinical examination: With special emphasis on particular symptoms as persistent knee instability, knee stiffness or pain, swelling, and limitation of movement beside the presence or absence of trauma or inflammatory lesions or new injury of the knee.

\section{MRI interpretation:}

Knees were imaged using a dedicated knee coil in a $1.5 T$ MRI scanner (Ingenia Philips, The Netherlands) devices. The patient was positioned supine, with the affected extremity in the knee coil. The head was outside the magnet. The extremity was in slight external rotation of about 15 degrees.

\section{Each examination consisted of:}

- Sagittal T1 weighted Fast Spin Echo (FSE) images [with repetition time (TR) $600 \mathrm{~ms}$ and echo time (TE) $15 \mathrm{~ms}]$.

- Axial and sagittal T2 weighted FSE images (with TR 4000ms and TE 90ms).

- Sagittal proton density weighted images (with TR over $2000 \mathrm{~ms}$ and TE $10-20 \mathrm{~ms}$ ).

- Coronal Short Time Inversion Recovery Images (STIR) [with TR over $4000 \mathrm{~ms}$ and TE $120 \mathrm{~ms}$ ].

- Coronal T2 weighted images with fat suppression (with TR over $3000 \mathrm{~ms}$ and TE $80 \mathrm{~ms}$ ).
- Slice thickness was $4.0 \mathrm{~mm}$ in all sequences.

- Inter slice gap $1 \mathrm{~mm}$.

- Field of View (FOV): $14-16 \mathrm{~cm}$ depending on the size of the patient.

- Matrix: 2256 X 256.

- Flip angle $=25^{\circ}$.

- Total scanning time was approximately 20 minutes.

The MR images were interpreted and the following findings were recorded:

1- Continuity and signal intensity of the anterior cruciate ligament graft in sagittal and coronal proton STIR images; signal intensity of the graft was graded as low when similar to the posterior cruciate ligament, intermediate when similar to the articular cartilage, and high when similar to subcutaneous fat.

2- Signal intensity and amount of periligamentous tissue between and around the ligamentous graft on sagittal and coronal proton density-, T1-, T2weighted, and STIR images.

3- Amount of fluid in the knee joint on oblique sagittal STIR images graded as normal, minimal, mild, moderate or marked effusion.

4- Position of the femoral and tibial bone tunnels on oblique sagittal MR images.

5- Any additional findings including cysts, bone marrow edema, localized anterior arthrofibrosis (Cyclops lesion), and status of the menisci.

6- Artifacts from the metallic fixation devices.

\section{Results}

This study included 30 patients with average age at diagnosis being 30 years old (range: 19-58 years), with the patients distributed in the age groups as follows: <20 years 1 patient $(3 \%), 21$ 30 years 20 patients $(67 \%)$ (the most common group), 31-40 years 6 patients (20), <40 years 3 patients $(10 \%)$.

Out of the thirty patients, 26 patients (87\%) had ACL in the right knee while the remaining 4 patients $(13 \%)$ had ACL in the left knee.

The 30 patients underwent MRI imaging of the knee in the period between January 2017 \& October 2018 referred to the Diagnostic Radiology Department, Faculty of Medicine, Ain-Shams University.

Most of the patients were symptomatic at presentation with the symptoms ranged between: Knee 
pain in 30 patients $(100 \%)$, joint instability in 24 patients $(80 \%)$, limited movement in 5 patients $(17 \%)$, and joint swelling in 7 patients $(23 \%)$, the data is showed in (Table 1).

N.B: More than one symptom was encountered among patients, e.g. pain and instability or pain and swelling, etc. which is shown in (Table 1).

Table (1): Clinical presentation of patients at diagnosis.

\begin{tabular}{lcc}
\hline Initial complaint & Number of patients & Precentage \\
\hline Knee pain & 30 & $100 \%$ \\
Knee swelling & 7 & $23 \%$ \\
Joint instability & 24 & $80 \%$ \\
Movement limitation & 5 & $17 \%$ \\
Recent trauma & 20 & $67 \%$ \\
\hline
\end{tabular}

- As regard the cause of instability in our study, these are summarized in (Table 2):

Table (2): Summary of causes of instability in our study.

\begin{tabular}{lcc}
\hline Cause of instability & $\begin{array}{c}\text { Present } \\
(\mathrm{N}, \%)\end{array}$ & $\begin{array}{c}\text { Absent } \\
(\mathrm{N}, \%)\end{array}$ \\
\hline Abnormal mechanical loads & $11(37 \%)$ & $19(63 \%)$ \\
Non anatomical tunnel placement: & $4(13 \%)$ & $202(74 \%)$ \\
$\quad$ Tibial tunnel & $4(13 \%)$ & \\
$\quad$ Femoral tunnel & $2(6 \%)$ & $28(94 \%)$ \\
Early aggressive rehabilitation & & \\
Misdiagnosed injury: & $2(6 \%)$ & $27(90 \%)$ \\
$\quad$ PCL & $1(3 \%)$ & \\
$\quad$ Med. Collat. Lig. &
\end{tabular}

- Graft continuity: As regard the graft continuity 20 patients $(67 \%)$ had intact grafts while the remaining 10 patients (33\%) had disrupted grafts.

- Graft signal intensity: The graft signal intensity findings were as follows: Low signal (normal) in 15 patients $(50 \%)$, intermediate (impinged) or (partial tear) in 8 patients $(27 \%)$, and absent graft tissue (complete tear) in 7 patients $(23 \%)$ as summarized in (Table 3 ).

Table (3): Graft signal intensity findings among patients.

\begin{tabular}{lcc}
\hline Graft signal intensity & Number of patients & Precentage \\
\hline - Low signal (normal) & 15 & $50 \%$ \\
- Intermediate signal & 8 & $27 \%$ \\
- Absent graft tissue & 7 & $23 \%$ \\
(complete tear) & & \\
\hline
\end{tabular}

- Tunnel widening: The tunnel widening was present in only 5 patients (17\%) while the remaining 25 patients $(83 \%)$ have normal tunnel width (Table 4).

- Tibial cystic degeneration: Tibial cystic degeneration was found in only 3 patients $(10 \%)$ while the remaining 27 patients $(90 \%)$ were free (Table 4).

-Arthrofibrosis and Cyclops: As for the presence of arthrofibrosis and cyclops, it was found in 2 patients $(6.6 \%)$ while the remaining 28 patients $(93.4 \%)$ were free (Table 4$)$.

- Graft tear: The graft was partially torn in 3 patients $(10 \%)$ and completely torn in 7 patients (23\%) (Table 4).

Table (4): Summary of complicated ACL grafts.

\begin{tabular}{lcc}
\hline Finding & $\begin{array}{c}\text { Number } \\
\text { of patients }\end{array}$ & Precentage \\
\hline Tunnel widening & 5 & $17 \%$ \\
Tibial cystic degeneration & 3 & $10 \%$ \\
Arthrofibrosis and cyclops & 2 & $7 \%$ \\
Partial graft tear & 3 & $10 \%$ \\
Complete graft tear & 7 & $23 \%$ \\
\hline
\end{tabular}

- Meniscal injury: As regard the meniscal injuries, the medial meniscus was torn in 7 patients $(23 \%)$, degenerated in the posterior horn in 12 patients $(40 \%)$. While the lateral meniscus was torn in 1 (3\%) patient and degenerated in $2(7 \%)$ patients which is summarized in (Table 5).

Table (5): Summary of meniscal injury among patients.

\begin{tabular}{lcc}
\hline Type of injury & $\begin{array}{c}\text { Medial } \\
\text { meniscus }\end{array}$ & $\begin{array}{c}\text { Lateral } \\
\text { meniscus }\end{array}$ \\
\hline Tear & $7(24 \%)$ & $1(3 \%)$ \\
Degeneration & $12(40 \%)$ & $2(6 \%)$ \\
\hline
\end{tabular}

- Synovial effusion: Synovial effusion was absent in 12 patients $(40 \%)$, minimal in 6 patients $(20 \%)$, mild in 10 patients $(33 \%)$ and moderate in 2 patients $(7 \%)$.

- Bone marrow edema: Bone marrow edema was observed in 3 patients $(10 \%)$ while the remaining 27 patients $(90 \%)$ were free. 

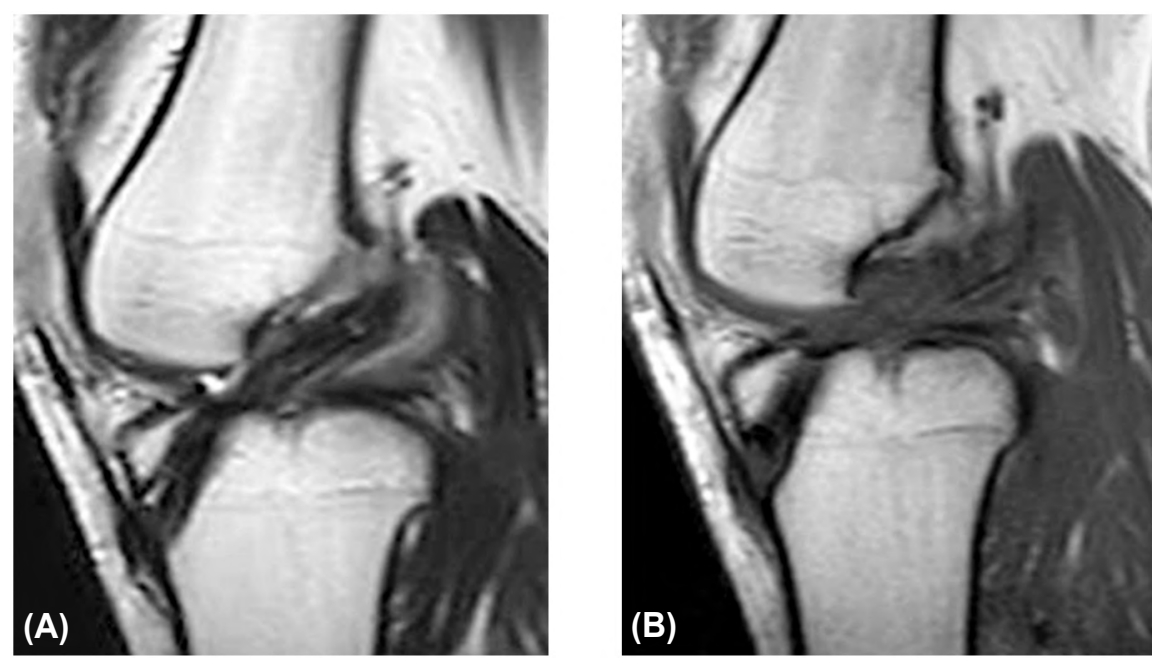

Fig. (1): 30 years old patient complaining of knee pain and instability 10 months after ACL reconstruction. (A) Sagittal FSE T2-weighted MR shows the graft is impinged by intercondylar notch and (B) Shows anterior malposition of tibial tunnel.
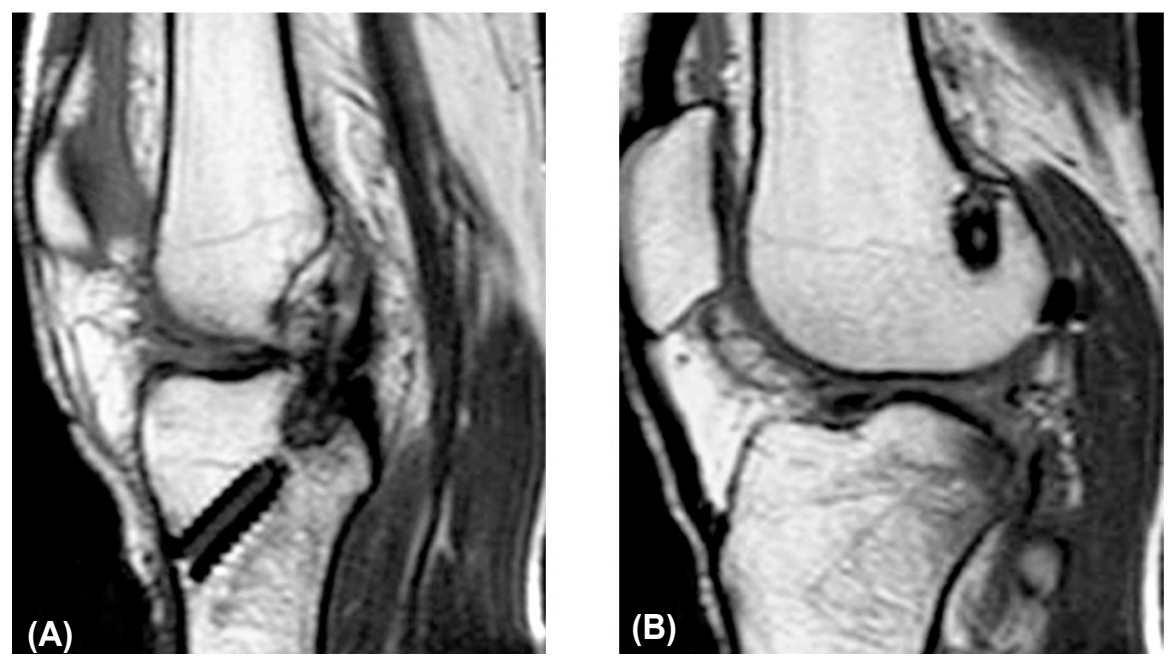

Fig. (2): 19 years old patient 2 year after ACL reconstruction presented with recurrent knee pain and swelling. (A) Sagittal FSE-T1 image shows posteriorly displaced tibial tunnel also, there is tibia bone marrow edema $(B)$.
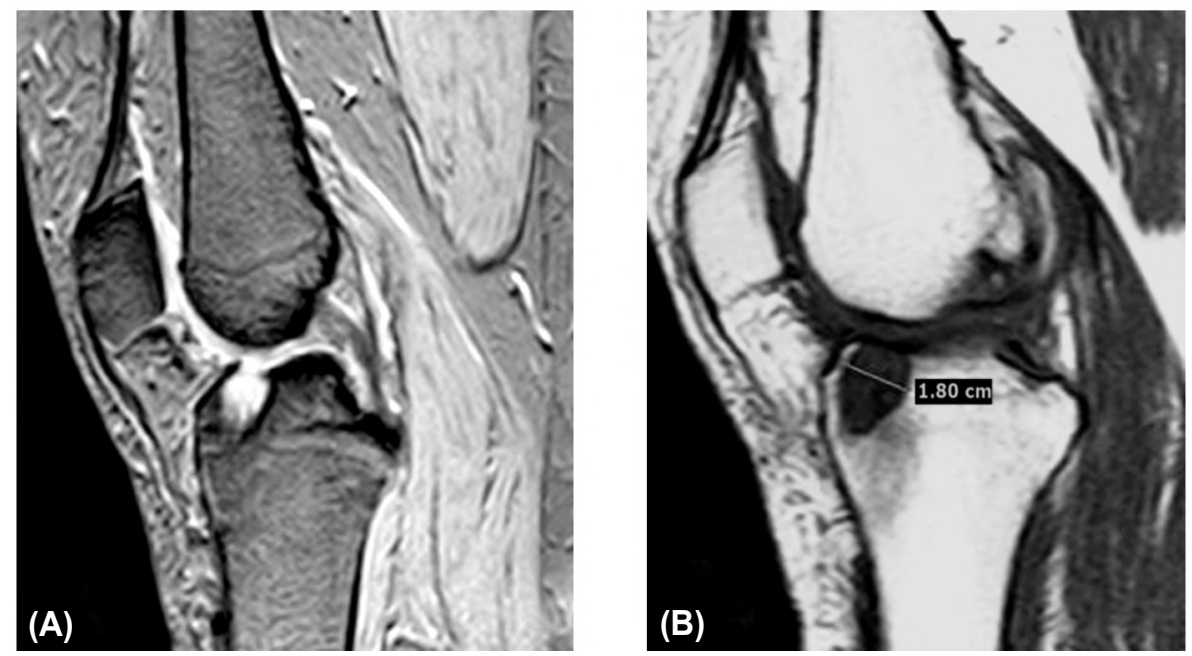

Fig. (3): 32 years old patient one year after ACL reconstruction complaining of recurrent knee pain and limited extension (A) and (B) sagittal GRE and FSE-T1 MR images demonstrate anteriorly displaced tibial tunnel with tunnel widening (measuring $18 \mathrm{~mm}$ ). 


\section{Discussion}

MRI is critical in evaluation of the postoperative knee, particularly in the assessment of the symptomatic anterior cruciate ligament reconstructed knee. MRI allows direct evaluation of the anterior cruciate ligament graft, the bone tunnels, and of additional disorders of the knee. MRI can demonstrate graft failure, bone tunnel position, impingement, and arthrofibrosis, as well as other causes of unsatisfactory outcome [5].

Even though ACL reconstruction is a very widely used operation with a very satisfactory success rate which allows the majority of active patients involved in sports activities to resume their pre-operative levels, the persistence of a certain rotatory joint instability is obviously observed and might produce subsequent joint complications [6].

In the paper published by Collins et al. [7], over 2,370 patients diagnosed with an ACL injury between 2001 and 2007 in Boston. The sex distribution was $47 \%$ female and $53 \%$ male. In our study all patients were male which is different from Collins et al. [7], and this could be attributed to lesser number of patients in our study and different level of activity and contact sports practionar in our locality compared by western countries.

The age distribution encountered by Collins \& Colleagues [7] the average age was 47.1 (30 in our study) $10 \%$ was $20-29$ at the time of ACL injury, $22 \%$ was $30-39,27 \%$ was $40-49$ (the most common group), $21 \%$ was $50-59,13 \%$ was $60-69$ and $6.5 \%$ was 70 or older. In our study mean age at diagnosis being 30 years old (range: 19-58 years), with the patients distributed in the age groups as follows: $<20$ years $3.3 \%, 21-30$ years $66.6 \%$ (the most common group), $31-40$ years $20 \%$, and $<40$ years $10 \%$ which was in concordance with Collins \& et al., [7] where mean age was 32 years (range: $24-$ 54 years) $<30$ years $38.5 \%, 30-<40$ years $50 \%, 40$ $<50$ years $7.7 \%$, and $\geq 503.8 \%$ which could be explained by the higher level of activity among western population above 40 years and their higher life expectancy compared to our locality.

In the study done by Weber et al., [8] in New York over 18 patients the incidence of ACL graft in the right knee was 6/18 (33\%) and left was 12/18 $(67 \%)$, in our study 26 patients $(86.7 \%)$ had ACL graft in the right knee while the remaining 4 patients $(13.3 \%)$ had ACL graft in the left knee.

The period elapsed between the reconstruction \& MRI study in the paper published by Kamel and
Darwish [9] over 32 patients was less than 1 year in $40.6 \%$ and more than 1 year in $59.4 \%$. In our study the period was between (28-320) weeks with the average period being 70 weeks, with the patients distributed in the groups as follows: 6-12 months 15 patients (50\%), 1-2 years 10 patients (33.3\%) (the most common group) $\&>2$ years 5 patients $(17 \%)$.

As regard patient symptoms in 2011, Galal et al., published data regarding 42 patients showing symptoms at diagnosis as follows pain in (100\%), instability \pm locking in (75\%), swelling in (52\%), clicking and stiffness in $29.16 \%$ and failure to regain full extension $(20.8 \%)$. In our study most of 30 patients were symptomatic at presentation and symptoms were knee pain in patients $(100 \%)$, joint instability in (80\%), limited movement in $(17 \%)$ and joint swelling in (23\%).

In the immediate post-operative period on sagittal MR images, the intra-articular portion of the graft appears as a thick band of homogeneously low signal intensity that extends parallel and posterior to the intercondylar notch [13] between the first 1-3 months after ACL reconstruction, a variable amount of increased signal is observed between intact fibers on all MR imaging sequences, due to revascularization and increased water content [10]

Bellelli et al., [11] summarized the ACL signal intensity changes to be during the first 1-3 months the graft signal is low due to peri-ligamentous proliferation, at 3-9 months the graft signal becomes progressively hyperintense due to intraligamentous proliferation while after 12 months complete ligamentization occurs due to definitive healing with incorporation [10]. In our study 8 patients (27\%) showed intermediate signal intensity with preligament proliferation consistent with incomplete graft maturation.

The ACL graft tears are diagnosed by several primary and secondary signs. The primary signs include morphologic or signal intensity findings as absent or discontinuous ACL graft fiber [11] Secondary signs of ACL tear include the anterior drawer sign, a buckled PCL, uncovering of the PHLM, and bone marrow edema in a characteristic location [12]. In our study bone marrow edema one of the secondary signs of ACL graft tear was observed in $3 / 30$ patients $(10 \%)$.

In our study 20 patients (67\%) had intact grafts while the remaining 10 patients (33\%) had disrupted grafts. 
Kamel and Darwish [9] showed diffuse increased signal in the region of the ACL graft on the proton density-weighted images were found in $45 \%$ of the full-thickness tears, $55 \%$ of partial-thickness tears, and $10 \%$ of intact grafts in our study the graft signal intensity findings were as follows: Low signal (normal) in 15 patients $(50 \%)$, intermediate with partial tear in 3 patients $(10 \%)$, intermediate with impingement in 5 patients $(17 \%)$, and complete tear in 7 patients $(23 \%)$.

Rayan et al., [12] stated the importance of optimal tunnel placement in affecting the integrity of ACL graft after reconstruction as incorrect positioning of either tibial or femoral tunnel is the most common reason for suboptimal outcome or failure of the ACL reconstruction [15]. In our study out of the 10 patients who showed ACL graft tear 3 patients $(30 \%)$ had partial tear ( 2 of those had abnormal femoral and tibial tunnel placement with only one having optimal tunnel placement), 7 patients had complete tear ( 5 of them had abnormal femoral or/and tibial tunnel placement).

If the tibial tunnel is positioned too far anteriorly the graft can become impinged on by the roof of the intercondylar notch and will show increased signal in the graft on T1-and T2-weighted sequences in the setting of notch impingement [14]. In our study we encountered impingement in $5 / 30$ patients $(16.6 \%)$ and the causes were: Improper femoral or tibial tunnel placement in $4 / 5$ patients $(80 \%)$ and the remaining patient $(20 \%)$ showed displaced interference screw despite normal femoral and tibial tunnel isometry.

According to El-Ameen et al., [13] in 2014 tunnel widening was present in $8 / 34$ patients $(23.5 \%)$, which was concomitant with our study as tunnel widening was present in only $5 / 30$ patients $(17 \%)$.

According to El-Ameen et al., [13] . In 2014 tibial cystic degeneration was found in only $2 / 34$ patients $(5.9 \%)$. Galal et al., Reported $2 / 48$ cases $(4.16 \%)$ tibial cystic degeneration. In our study only 3 patients $(10 \%)$ had tibial cystic degeneration.

El-Ameen et al., [13]. Found arthrofibrosis and Cyclops in 2/34 patients (5.9\%) in our study arthrofibrosis and cyclops were found in 2 patients (7\%) while the remaining 28 patients $(93 \%)$ were free.

\section{Conclusion:}

In our study we conclude that:

MRI is ideally suited for the evaluation of pain and instability in the post-operative ACL patient. Graft integrity and position can be determined. With the increasing prevalence of arthroscopic repair of the ACL, the importance of MRI in the evaluation of this patient population will increase.

We conclude that MRI of the knee is the modality of choice in assessing instability of the knee joint of the post-operative ACL reconstruction patient. MRI provides a non-invasive modality for evaluation of ACL graft fiber integrity and postoperative instability. ACL graft complications such as abnormal tunnel positioning, roof impingement, partial and complete graft tears, arthrofibrosis and tunnel synovial cysts, are reliably assessed by MRI.

\section{References}

1- RECHT M.P. and KRAMER J.: MR imaging of postoperative knee: A pictorial essay. Radiographic, 174: 76574, 2002.

2- PITTMAN G.: ACL Injuries Most Common in Football, Girls' Soccer. Available at http://www.medscape.com/ viewarticle/814247. Accessed:November 16, 2018.

3- WHITE L.M., KRAMER J. and RECHT M.P.: MR imaging evaluation of the postoperative knee: Ligaments, menisci, and articular cartilage. Skeletal Radial., 13: 110611, 2005.

4- ALMEKINDERS L.C., CHIAVETTA J.B. and CLARKE J.P.: Radiographic evaluation of anterior cruciate ligament graft failure with special reference to tibial tunnel placement. Arthroscopy, 14: 206-11, 2008.

5- WHITE L.M., KRAMER J. and RECHT M.P.: MR imaging evaluation of the postoperative knee: Ligaments, menisci, and articular cartilage. Skeletal Radiol., 34: 431$52,2005$.

6- NOYES F.R. and BARBER S.D.: The effect of a ligamentaugmentation device on allograft reconstructions for chronic ruptures of the anterior cruciate ligament. J. Bone Joint. Surg. Am., 74 (7): 960-73, 2012.

7- COLLINS J.E., KATZ J.N., DONNELL-FINK L.A., et al.: Cumulative incidence of ACL reconstruction after ACL injury in adults: Role of age, sex and race Am. J. Sports Med., 41 (3): 544-9, 2013.

8- WEBER W.N., NEUMANN C.H., BARAKOS J.A., et al.: Lateral tibial rim (segond) fractures MR imaging characteristics. Radiology, 180: 731-4, 2011.

9- KAMEL H. and DARWISH H.: Evaluation of anterior cruciate ligament repair using magnetic resonance imaging Medical Imaging and Radiology, ISSN 2054-1945 | Volume 2 | Article 6, 2014.

10- JANSSON K.A., KARJALAINEN P.T., HARILAINEN A., et al.: MRI of anterior cruciate repair with patellar and hamstring tendon autografts. Skeletal Radiol., 30: 8, 2001.

11- BELLELLI A., ADRIANI E., MAGHERITINI F., et al.: Synovial healing in reconstruction ligaments. Radiol. Med., 98: 454-61, 2009. 
12- RAYAN F., NANJAYAN S.K., QUAH C., et al.: Review of evolution of tunnel position in anterior cruciate ligament reconstruction World J. Orthop., 6 (2): 252-62, 2015.

13- EL AMEEN N.F., ABDEL GHANY H.S. and ABDEL
KADER M.G.: MRI assessment of tibial tunnel and its relation to complication following arthroscopic reconstruction of anterior cruciate ligament The Egyptian Journal of Radiology and Nuclear Medicine, 45: 811-7, 2014.

\section{دور التصوير بالرثين المغناطيسى فى تقيييم عدم الاستقرار

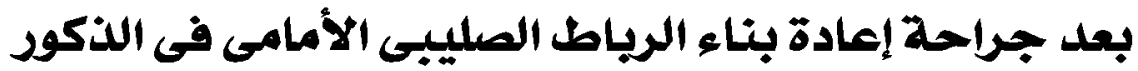

يعتبر الرياط الصلييى الآمامى الآكثر شيوعاً فى إعادة بناء الآربطة فى الركبة، من الصعب التقييم الإكلينيكى للرباط المليبى المعاد بناؤه،

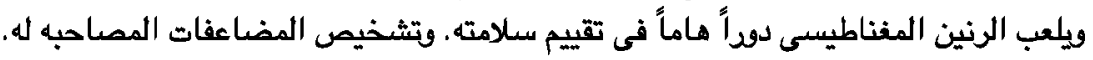

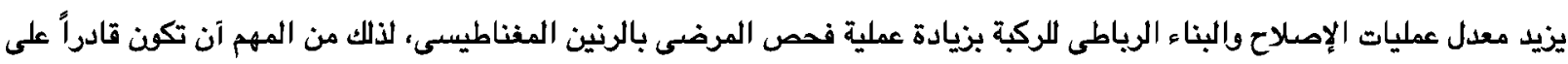

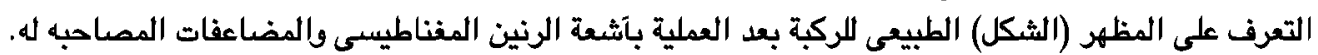

وقد هدفت هذه الدراسة في إظهار دود آشعة الرنين المغناطيسى فى تقييم إعادة بناء الآربطة الصلييية لمفصل الركبة. وقد إشتملت على بلى

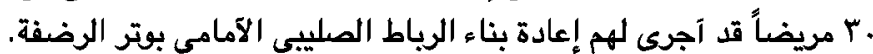

وقد ساعلا إستخدام الرنين المغناطيسى فى التقييم الاقيق للآربطة الصلييية التى تم بنائها.

في هذه الدراسة قد وجد إن نتائج البحث للرنين المغناطيسى قد آنصب فى صلابة (سلامة) الرباط المعاد بناؤه، ووضع النفق العظمى.

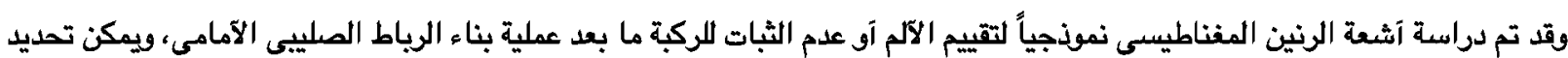

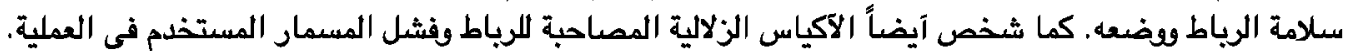
مع زيادة إنتشار الإصلاح للرياط الصلييى الآمامى بالمنظار. يتم زيادة آهمية الرينين المغناطيسى فى تقييم ذلك المرضى. 